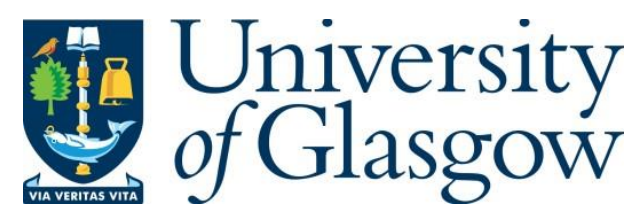

Joseph, S. et al. (2019) Fractures and bone health monitoring in boys with Duchenne muscular dystrophy managed within the Scottish Muscle Network. Neuromuscular Disorders, 29(1), pp. 59-66.

There may be differences between this version and the published version. You are advised to consult the publisher's version if you wish to cite from it.

http://eprints.gla.ac.uk/174992/

Deposited on: 14 February 2019

Enlighten - Research publications by members of the University of Glasgow http://eprints.gla.ac.uk 
Fractures And Bone Health Monitoring In Boys With Duchenne Muscular Dystrophy Managed Within The Scottish Muscle Network

Shuko Joseph, Cunyi Wang, Marina DiMarco, lain Horrocks, Ishaq Abu-Arafeh, Alex Baxter, Nuno Cordeiro, Linda McLellan, Kenneth McWilliam, Karen Naismith, Elma Stephen, S. Faisal Ahmed, Sze Choong Wong

PII: S0960-8966(17)31316-0

DOI: https://doi.org/10.1016/j.nmd.2018.09.005

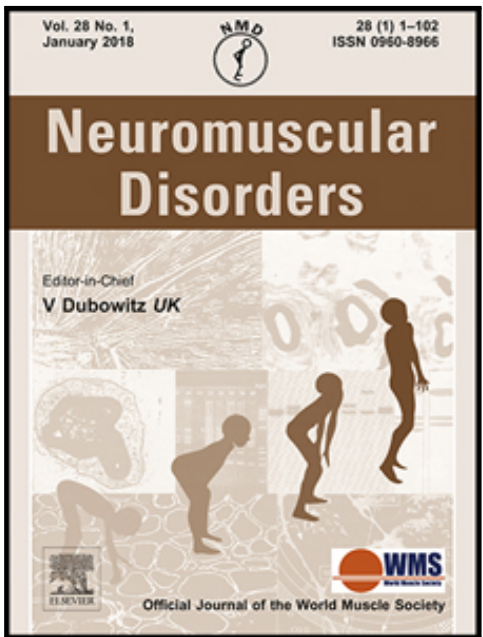

Reference: NMD 3611

To appear in: Neuromuscular Disorders

Received date: 11 September 2017

Revised date: $\quad 9$ September 2018 Accepted date: 21 September 2018

Please cite this article as: Shuko Joseph, Cunyi Wang, Marina DiMarco, lain Horrocks, Ishaq Abu-Arafeh, Alex Baxter, Nuno Cordeiro, Linda McLellan, Kenneth McWilliam, Karen Naismith, Elma Stephen, S. Faisal Ahmed, Sze Choong Wong, Fractures And Bone Health Monitoring In Boys With Duchenne Muscular Dystrophy Managed Within The Scottish Muscle Network, Neuromuscular Disorders (2018), doi: https://doi.org/10.1016/j.nmd.2018.09.005

This is a PDF file of an unedited manuscript that has been accepted for publication. As a service to our customers we are providing this early version of the manuscript. The manuscript will undergo copyediting, typesetting, and review of the resulting proof before it is published in its final form. Please note that during the production process errors may be discovered which could affect the content, and all legal disclaimers that apply to the journal pertain. 


\section{Fractures And Bone Health Monitoring In Boys With Duchenne Muscular Dystrophy Managed Within The Scottish Muscle Network}

Shuko Joseph ${ }^{1,2}$, Cunyi Wang ${ }^{1,3}$, Marina DiMarco ${ }^{4}$, lain Horrocks ${ }^{2}$, Ishaq Abu-Arafeh ${ }^{5}$, Alex Baxter ${ }^{6}$, Nuno Cordeiro ${ }^{7}$, Linda McLellan ${ }^{8}$, Kenneth McWilliam ${ }^{6}$, Karen Naismith ${ }^{9}$, Elma Stephen ${ }^{10}$, S. Faisal Ahmed ${ }^{1}$, Sze Choong Wong ${ }^{1}$

${ }^{1}$ Developmental Endocrinology Research Group, Royal Hospital for Children, Glasgow, ${ }^{2}$ Paediatric Neurosciences Research Group, Royal Hospital for Children, Glasgow,

${ }^{3}$ School of Mathematics and Statistics, University of Glasgow,

${ }^{4}$ Scottish Muscle Network, Queen Elizabeth University Hospital, Glasgow,

${ }^{5}$ Department of Paediatrics, Forth Valley Royal Hospital, Stirlingshire,

${ }^{6}$ Department of Paediatric Neurology, Royal Hospital for Sick Children, Edinburgh,

${ }^{7}$ Department of Paediatrics, Crosshouse Hospital, Ayrshire,

${ }^{8}$ Department of Paediatrics, Raigmore Hospital, Inverness,

${ }^{9}$ Department of Paediatrics, Ninewells Hospital, Dundee,

${ }^{10}$ Department of Paediatrics, Royal Aberdeen Children's Hospital, Aberdeen, United Kingdom

\section{Address for correspondence}

Dr. Sze Choong Wong,

Developmental Endocrinology Research Group, Royal Hospital for Children

1345 Govan Road, Glasgow G51 4TF United Kingdom

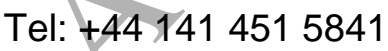

Email: jarod.wong@glasgow.ac.uk

Running Title: Fractures in DMD

Word Count: 3056 words (excluding abstract, references, legends)

Abstract: 199 words 
Keywords: Bone mineral density; Glucocorticoid; Osteoporosis; Skeletal fragility; Vitamin D Highlights

- A high rate of radiologically confirmed symptomatic fractures (48\%) was identified.

- Non-vertebral fractures occurred predominantly at femur and tibia after minor falls.

- $\quad$ DMD bone monitoring is currently inconsistent despite consensus guidance.

\section{Abstract}

There are limited reports of radiologically confirmed fractures and bone health monitoring in with Duchenne Muscular Dystrophy. We performed a retrospective study of 91 boys, with a median age of 11.0 years, who are currently managed in Scotland with the aim to assess the frequency of radiologically confirmed fractures and report on bone health monitoring in relation to International Care Consensus Guidance. Of these boys, 59 (65\%) were receiving glucocorticoid (GC) therapy and $23(25 \%)$ had received previous treatment. Of those currently on GC, 37 (63\%) had an assessment of bone mineral density and none had routine imaging for vertebral fractures during the study period. Of the 91 boys, 44 (48\%) had sustained at least one symptomatic radiographically confirmed fracture. The probability of sustaining a first symptomatic fracture was $50 \%$ by 12.8 years old $(95 \% \mathrm{Cl}: 12.1,13.6)$. The most common sites for non-vertebral fracture were the femur and tibia. In this review of boys with $\mathrm{DMD}$, almost half had sustained at least one radiologically confirmed symptomatic fracture. There is a need for standardized bone health monitoring in DMD that includes routine imaging of the spine to identify vertebral fractures, given the persistence of insult to the skeleton in these boys.

\section{Introduction}

Duchenne Muscular Dystrophy is an X-linked recessive disorder occurring in 1 in 4000 live male births 1. DMD is a life-limiting disorder associated with progressive muscle inflammation, degeneration, fatty infiltration and fibrosis leading to progressive motor disability. Most affected boys will be wheel chair dependent by the age of 12 years. Glucocorticoid (GC) therapy is the only disease-modifying option, which has been shown to improve short-term muscle function and strength ${ }^{2}$ but other benefits including preservation 
of upper limb function, reduction in risk of scoliosis and preservation of cardiac function are reported with prolonged use ${ }^{3-5}$. However, prolonged use of GC is associated with abnormalities of growth and skeletal development ${ }^{6}$. Due to the high fracture frequency, several international workshops have developed consensus on monitoring and management of bone health in $\mathrm{DMD}$, including the need for vitamin $\mathrm{D}$ supplementation, regular monitoring of vitamin $D$ levels and evaluation of bone mass with dual energy absorptiometry (DXA) ${ }^{7-9}$. Previous studies have shown that fractures may lead to premature loss of ambulation and may be associated with severe and life threatening complications like fat embolism syndrome ${ }^{10}$.

Whilst it is recognized that fractures are common in these boys, it is difficult to be certain of the prevalence of fracture from published studies. Based on patient recall or case note review ${ }^{11-17}$, fractures have been reported in over $40 \%$ of boys and young men. However, it is not clear from these reports if complete case ascertainment was achieved. In addition, most published studies are from a single site.

In Scotland, the care of boys with DMD is delivered locally in seven paediatric centres using nationally agreed standards within the framework of a national managed clinical network. All radiological imaging is available for sharing on a single national platform. The aim of this study was to utilize these opportunities and assess the occurrence of radiologically confirmed symptomatic fractures in boys and adolescents with DMD. In addition, a secondary aim of the study was to report on bone health monitoring in boys managed in Scotland.

\section{Methods}

A retrospective review of bone health of 91 boys with DMD currently managed in the 7 centres supported by the Scottish Muscle Network (SMN, www.smn.scot.nhs.uk) was performed as part of a service evaluation in December 2015. Cases were identified from a registry held by the SMN and cross-checked with the lead neuromuscular clinicians in the 7 centres in Scotland. Information on all cases from diagnosis to last clinic visit, closest to December 2015 were collected. The diagnosis of DMD was confirmed by DNA diagnostic 
technique and/or confirmatory muscle biopsy.

Fractures were identified from the national radiological archive report (Picture Archiving and Communication System (PACS), GE Systems, Milwalkee, Wis) and classified into vertebral fracture (VF) and non-VF. X-rays were performed as clinically indicated due to symptoms of limb pain, back pain, documented injuries or swelling. Routine screening lateral thoracolumbar spine x-rays was not adopted as part of clinical care during the period of study. All X-rays were reported by a consultant radiologist at the local centre. Detailed characteristics of fractures were collected from case notes including mechanism of fracture and clinical characteristics at the time of fracture including age, GC regimen and duration, mobility status, vitamin D levels, dual energy x-ray absorptiometry (DXA). Non-ambulant status was defined by a continuous use of a wheelchair. DXA was performed for total body (TB) and lumbar spine (LS) bone mineral content (BMC) adjusted for bone area (BAr) as previously described, using Lunar Prodigy (GE Medical Systems, Waukesha, Wis., USA) ${ }^{18}$. Anthropometric measurements (height, body mass index) were converted into standard deviation score (SDS) using the 1990 UK growth reference data ${ }^{19,20}$. Ambulant boys were measured by standing height whereas non-ambulant boys who had growth monitoring were measured by arm span.

\section{Statistics}

Statistical analysis was conducted using IBM SPSS Statistics Software Version 22 (SPSS Inc, Chicago). Results are reported as median $\left(25^{\text {th }}\right.$ and $75^{\text {th }}$ centile). The effect of age and the duration of GC therapy on the probability of fractures was determined by Kaplan-Meier analysis in median (95\% confidence interval). For the analysis of time to first fracture (VF and non-VF) against age and GC duration, censored cases were included. In addition, boys who discontinued GC were also included. A level of $p<0.05$ was used to denote statistical significance.

\section{Results}




\section{Population Characteristics}

Details of all 91 boys at last clinic visit are summarised in Table 1. The median age of the cohort was 11.3 years $(7.8,15.0)$. Of the $91,46(51 \%)$ were non-ambulant. Median height SDS at last clinic visit was available in 76 boys and was $-1.4(-2.7,-0.8)$. Of the 76,19 $(25 \%)$ had a height SDS $<-2.0$. Median BMI SDS was $+1.6(0.7,+2.2)$ with $13(30 \%)$ having a BMI SDS > +2.0.

\section{Glucocorticoid therapy}

Of the $91,59(65 \%)$ were on GC therapy at last clinic visit and $23(25 \%)$ were previously treated with GC. Median length of GC in the boys who were previously treated was 4.2 years $(2.8,6.6)$. Of the 23 who were previously treated with $G C, 17$ discontinued at the time of loss of ambulation at a median age of 10.2 years $(9.0,11.5)$. Five discontinued after loss of ambulation due to excessive weight gain and 1 discontinued due to severe behavioural issues whilst still ambulant at 9.6 years of age. There were four different GC regimens used [Table 1]. Of the 59 on GC, 23 (40\%) were treated with daily Deflazacort and only one boy was managed on pulsed Deflazacort. GC regimen was unknown for six who were enrolled in a randomized trial with the aim to evaluate the optimal GC regimen in DMD. All six were however treated with GC. Of the 32 who were not currently on GC, 9 were younger GC naïve boys ( $\leq 5$ years). Median hydrocortisone equivalent was highest in daily Deflazacort, followed by daily Prednisolone and pulsed Prednisolone regimen at a median dose of $94.0 \mathrm{mg} / \mathrm{m}^{2} /$ day $(45.0,138.0), 69.5 \mathrm{mg} / \mathrm{m}^{2} /$ day $(64.8,75.8), 31.0 \mathrm{mg} / \mathrm{m}^{2} /$ day $(13.5$, 37.0), respectively.

\section{Bone health monitoring}

Of the $91,46(51 \%)$ had plasma 25 hydroxy-vitamin D levels measured in the last 12 months. Median vitamin D level was $49 \mathrm{nmol} / \mathrm{L}(23,143)$. Of the $91,63(69 \%)$ had at least one DXA assessment. Of the 28 who have never had any DXA assessment, 8 (29\%) were GC naïve boys $\leq 5$ years. Of the 59 currently on GC, $37(63 \%)$ had a DXA assessment in the 
last 2 years.

\section{Vitamin D therapy}

Of the $91,69(76 \%)$ were on vitamin D supplementation. Of the 59 currently on GC, $48(81 \%)$ were on vitamin D supplementation. Median vitamin D dose was 800 IU daily (400, 1400).

\section{Bisphosphonate therapy}

Of the $91,10(11 \%)$ were receiving bisphosphonate therapy. Of the $10,8(80 \%)$ were receiving intravenous bisphosphonate therapy, of whom six were on zoledronate, and two on pamidronate. The indications for treatment were symptomatic VFs in 7 boys and multiple long bone fractures in another boy. The remaining two boys $(20 \%)$ were receiving oral risedronate. One was commenced after a long bone fracture, and the other was started as prophylaxis, however, subsequently developed femoral fracture on treatment. Two other boys were previously treated with bisphosphonate. Of these, one boy received a single dose of pamidronate for back pain with low LS bone mineral density SDS -2.5 without evidence of VF on X-ray. The other boy completed two years of 4 monthly pamidronate for symptomatic VF.

\section{Testosterone therapy}

Of the $91,29(32 \%)$ were 14 years or older and of this group, pubertal assessment was only documented in 14 (48\%), all following referral to paediatric endocrinologist as a result of parental or clinician concern about delayed puberty. Of the 29, 11 (79\%) were prepubertal with testes volume of less than $4 \mathrm{ml}$. Of these 11 boys, five were on intramuscular testosterone and two on oral testosterone for pubertal induction. None had received growth hormone therapy. 
Of the $91,44(48 \%)$ sustained a total of 51 fractures. Of the $91,36(40 \%)$ had nonVFs, 7 had symptomatic VFs (8\%) and 1 had both non-VFs and symptomatic VFs. Of the 44, $5(11 \%)$ sustained multiple fractures. The number of fractures sustained per individual ranged from 1 to 4 . There were 43 non-VF episodes and these occurred predominantly in the lower limb in 31 (72\%) [Figure 1] with the most common site being the femur in 14 (33\%) followed by tibia in $12(30 \%)$. Of the 43 non-VF episodes, $36(84 \%)$ were fragility fractures ${ }^{21}$ with $26(61 \%)$ occurring after a fall from a standing position and $10(23 \%)$ occurring in nonambulant boys following a fall from a sitting position. In 6 (14\%), non-VFs occurred following a history of minor trauma and in 1 boy mechanism of injury was not documented. All the 8 boys with symptomatic VFs presented with multiple painful VFs. The location of fractures included multiple thoracic and lumbar in 6 , multiple lumbar in 1 and multiple thoracic in 1 . A boy sustained three long bone fractures before the diagnosis of symptomatic VF. The first fracture was fracture of the tibia aged 2.1 years due to a fall from standing, prior to treatment with GC.

Of the 36 boys who sustained non-VFs, 20 (56\%) were ambulant prior to the fracture and 7 (35\%) never regained ambulation following the fracture. 6 out of the $8(75 \%)$ boys were ambulant at the time that symptomatic VFs were diagnosed. None of the boys lost ambulation following diagnosis of symptomatic VF.

Age and fracture

The probability of developing a first symptomatic fracture (non-VF or symptomatic VF) was $50 \%$ by 12.8 years old $(95 \% \mathrm{Cl} 12.1$ to 13.6$)$ [Figure 2a]. The probability of developing non-VF was $50 \%$ by 13.6 years old (95\% Cl 12.3 to 14.8$)$. Non-VFs occurred over a wide age range of 2.0 to 17.4 years. The probability of developing symptomatic VF was $50 \%$ at 11.4 years old $(95 \% \mathrm{Cl} 10.0$ to 12.4$)$. Symptomatic VFs occurred over an age range of 5.6 to 15.9 years.

GC duration and fracture 
The probability of developing a first symptomatic fracture (non-VF or symptomatic VF) was $50 \%$ after 6.5 years of GC exposure (95\% Cl 5.4 to 7.5$)$ [Fig. 2b]. The probability of developing non-VF was $50 \%$ after 8.2 years of GC exposure (95\% Cl 6.2 to 10.2$)$. Seven non-VFs occurred in 26 ambulant GC-naïve boys with a median age at fracture of 3.5 years $(2.0,10.1)$. In contrast, symptomatic VFs only occurred in the GC-treated cohort. There was a latency of 2.3 years before the development of the first symptomatic VF. The probability of developing symptomatic VF was $50 \%$ at 3.7 years of GC exposure ( $95 \% \mathrm{Cl} 2.8$ to 5.3 ).y

\section{Vitamin $D, D X A$ and fracture}

Of the 51 fracture events, $33(65 \%)$ had 25 hydroxy-vitamin D measured at the time of fracture. Median 25 hydroxy-vitamin D concentration at time of fracture was $49 \mathrm{nmol} / \mathrm{L}$ $(24,69)$. Of the $33,3(9 \%)$ had measurements $<25 \mathrm{nmol} / \mathrm{L}$. Of the 47 who did not sustain any fractures, median 25 hydroxy-vitamin $D$ at last visit was $49 \mathrm{nmol} / \mathrm{L}(20,125)$.

Of the 51 fracture events, DXA TB BMC SDS and LS BMC SDS within six months of fracture were available in $18(35 \%)$ and $17(33 \%)$, respectively. Of the 13 with non-VFs who had a DXA within 6 months of the fracture, only one had TB BMC SDS $<-2.0$. Of the 5 with VFs who had a DXA within 6 months of the fracture, similarly only one had TB BMC SDS and LS BMC SDS $<-2$.

\section{Discussion}

This study of a contemporary group of boys with DMD managed in Scotland showed that almost half of the group had sustained at least one fracture and almost $9 \%$ of boys had presented with severe painful VFs. The mechanisms of injury suggest that $84 \%$ of non-VFs in our DMD boys were classified as fragility fractures, occurring following a fall from standing height or less ${ }^{21}$. Our study also showed that bone monitoring in Scotland according to current international consensus remains inconsistent, although it is unclear if this is an issue in other regions ${ }^{7-9}$. Only half of the cohort had vitamin $D$ levels measured in the previous twelve months and only approximately $60 \%$ of GC treated boys had a DXA scan in the previous two years. 
When compared to the prevalence of fracture of $9 \%$ reported in a large cohort of healthy children in the United Kingdom, the prevalence of fracture in DMD in the current study $(48 \%)$ is clearly much higher ${ }^{22}$. In healthy children, upper limb long bone fractures at radius and ulna are the most common sites. In contrast, the two most common sites of fractures in the current cohort are femur and tibia ${ }^{22}$. A previous study has reported that lower limb fractures are the most common non-VFs but to the best of our knowledge detailed information on fracture sites in DMD have not been reported ${ }^{23}$. Compared to published studies of fractures in DMD, the frequency of non-VFs of $40 \%$ in the current study appears to be higher than the reported frequency of $23-30 \%$, although a recent study has also reported similar frequencies of non-VF ${ }^{24}$. We believe that the frequency of non-VF in the current study is robust given that we included cases that were radiologically confirmed.

The prevalence of VFs of almost $9 \%$ in the current study is much lower than the reported $18-76 \%$ in published literature in DMD ${ }^{15-17,23-27}$. Several factors could explain the differences in fracture occurrence including number of cases, GC regimen and dose, duration of treatment/follow-up and method of VF identification. Ten percent of the study cohort was also GC naïve. In recent studies, VF was detected in $53-76 \%$ in groups of boys on daily GC for at least three years when routine spine imaging was incorporated as part of bone health monitoring 24,25 . During the study period, none of the Scottish centres included routine spine imaging for VF. We believe that the frequency of almost $9 \%$ of VF presenting with significant pain in our cohort represents a gross underestimation in these boys. It is now well recognized that VF in children with chronic conditions are often asymptomatic ${ }^{26-28}$. Since 2016, we have revised the bone monitoring guidance of the Scottish Muscle Network, to incorporate routine thoracolumbar spine $\mathrm{x}$-rays (at least every 2 years) to detect VF ${ }^{24}$.

The frequency of VF up to $16 \%$ is reported at diagnosis in other groups of children with treated with GC where systematic screening with spine x-rays was conducted ${ }^{28-30}$. In childhood leukaemia, where intermittent GC is used, almost a quarter developed VF over a period of four years when a routine screening programme with spine $x$-rays was in place ${ }^{30}$. Vertebral reshaping is possible in some children with leukaemia or other children with 
chronic conditions who develop VF during shorter duration of GC therapy ${ }^{6,31,33,34}$. On the other hand, results from a retrospective study suggest that there is absent vertebral reshaping after diagnosis of VF in DMD which may be due to the prolonged period of GC therapy and irreversibility of the skeletal insult ${ }^{24}$. In our current review, we identified that delayed puberty is very common and present in almost $80 \%$ of older adolescents who have had clinical assessment of puberty following referral to paediatric endocrinology ${ }^{35}$. However, puberty was only documented in half the cohort of boys age 14 years and older. The prevalence of delayed puberty in these GC treated boys is therefore currently stilt unknown. Testosterone leads to increased bone mass by increasing periosteal expansion ${ }^{36-38}$ and pubertal delay will no doubt contribute in part to poor bone development in these adolescents. Emerging evidence suggests that these boys have persistent hypogonadism, and may therefore have long-term consequences to the skeleton even in adulthood ${ }^{39}$. There are limited studies on the effects of testosterone on skeletal development and growth in boys with DMD but this deserves greater attention ${ }^{39}$. The importance of assessment and management of delayed puberty in these boys is addressed in our updated bone monitoring guidance, which recommends routine pubertal assessment from the age of 13 years, ideally by a paediatric endocrinologist. Management of puberty with testosterone from the age of 14 years building up to adult doses over a period of 2 to 3 years is currently our clinical practice.

It is worth noting that the median age of loss of ambulation in our national cohort of boys with DMD appears to be younger than those reported in some recent literature ${ }^{40}$. In contrast to a recent report ${ }^{16}$, we did not find increased fracture incidence around the time of loss of ambulation, even though the age at loss of ambulation in our national cohort appears to be similar to that study and also other reports ${ }^{41}$. Some of the other published studies reporting a much later age of loss of ambulation are either from relatively small cohorts or did not include censored cases, thereby creating a bias of excluding those cases with a more severe phenotype or less responsive to $\mathrm{GC}^{23,42,43}$. The number of subjects in this study poses limitation in applying multivariable analysis to explore the influence of covariates on fracture risk. For example, the influence of different GC regimens, bisphosphonates, 
testosterone therapies, pubertal status, vitamin $D$ levels and bone mineral density will require exploration in a larger cohort. The complex interplay between underlying muscle weakness and GC therapy, together with other factors that may impact on bone health and therefore fracture risk in DMD needs to be teased out in well-designed research studies. Routine imaging with lateral thoracolumbar spine x-rays should be incorporated into such studies, and indeed in clinical monitoring of these boys ${ }^{44}$.

\section{Conclusion}

In summary, in one of the largest studies to date with complete ascertainment of boys with DMD, the current study reports a very high rate of radiologically confirmed fractures. The frequency of VF in our study is however likely to be a gross underestimation of the real frequency in this population. Bone monitoring in this national cohort is inconsistent and should now include routine imaging of the spine with lateral thoracolumbar spine x-rays. Routine pubertal assessment in these boys should be given attention in the neuromuscular clinics with timely referral to paediatric endocrinology for management of puberty. Multicentre prospective studies are required to clearly understand the determinants of asymptomatic as well as symptomatic fractures in this at-risk group.

\section{Acknowledgements}

SJ is supported by a clinical research training fellowship funded by the Chief Scientist Office Scotland, Muscular Dystrophy UK and Action Duchenne.

\section{Disclosure Statement}

The authors have no conflict of interest to disclose.

\section{References}

[1] Bushby K, Finkel R, Birnkrant DJ, et al. Diagnosis and management of Duchenne muscular dystrophy, part 1: diagnosis, and pharmacological and psychosocial management. Lancet Neurol 2010;9:77-93. 
[2] Matthews E, Brassington R, Kuntzer T, Jichi F, Manzur AY. Corticosteroids for the treatment of Duchenne muscular dystrophy. Cochrane Database Syst Rev 2016:CD003725. [3] Dec GW. Steroid therapy effectively delays Duchenne's cardiomyopathy. J Am Coll Cardiol 2013;61:955-56.

[4] Lebel DE, Corston JA, McAdam LC, Biggar WD, Alman BA. Glucocorticoid treatment for the prevention of scoliosis in children with Duchenne muscular dystrophy: long-term follow-up. J Bone Joint Surg Am 2013;95:1057-61.

[5] Biggar WD, Harris VA, Eliasoph L, Alman B. Long-term benefits of deflazacort treatment for boys with Duchenne muscular dystrophy in their second decade. Neuromuscul Disord 2006;16:249-55.

[6] Joseph S, McCarrison S, Wong SC. Skeletal Fragility in Children with Chronic Disease. Horm Res Paediatr 2016;86:71-82.

[7] Quinlivan R, Roper H, Davie M, Shaw NJ, McDonagh J, Bushby K. Report of a Muscular Dystrophy Campaign funded workshop Birmingham, UK, January 16th 2004. Osteoporosis in Duchenne muscular dystrophy; its prevalence, treatment and prevention. Neuromuscul Disord 2005;15:72-9.

[8] Biggar WD, Bachrach LK, Henderson RC, Kalkwarf H, Plotkin H, Wong BL. Bone health in Duchenne muscular dystrophy: a workshop report from the meeting in Cincinnati, Ohio, July 8, 2004. Neuromuscul Disord 2005;15:80-5.

[9] Quinlivan R, Shaw N, Bushby K. 170th ENMC International Workshop: bone protection for corticosteroid treated Duchenne muscular dystrophy. 27-29 November 2009, Naarden, The/Netherlands. Neuromuscul Disord 2010;20:761-9.

[10] McAdam LC, Rastogi A, Macleod K, Douglas Biggar W. Fat Embolism Syndrome following minor trauma in Duchenne muscular dystrophy. Neuromuscul Disord 2012;22:1035-9.

[11] Larson CM, Henderson RC. Bone mineral density and fractures in boys with Duchenne muscular dystrophy. J Pediatr Orthop 2000;20:71-4. 
[12] Vestergaard P, Glerup H, Steffensen BF, Rejnmark L, Rahbek J, Moseklide L. Fracture risk in patients with muscular dystrophy and spinal muscular atrophy. $\mathrm{J}$ Rehabil Med 2001;33:150-5.

[13] McDonald DG, Kinali M, Gallagher AC, et al. Fracture prevalence in Duchenne muscular dystrophy. Dev Med Child Neurol 2002;44:695-8.

[14] Henderson RC, Berglund LM, May R, et al. The relationship between fractures and DXA measures of BMD in the distal femur of children and adolescents with cerebral palsy or muscular dystrophy. J Bone Miner Res 2010;25:520-6.

[15] Mayo AL, Craven BC, McAdam LC, Biggar WD. Bone health in boys with Duchenne Muscular Dystrophy on long-term daily deflazacort therapy. Neuromuscul Disord 2012;22:1040-5.

[16] Perera N, Sampaio H, Woodhead H, Farrar M. Fracture in Duchenne Muscular Dystrophy: Natural History and Vitamin D Deficiency. J Child Neurol 2016;31:1181-7.

[17] Bothwell JE, Gordon KE, Dooley JM, MacSween J, Cummings EA, Salisbury S. Vertebral fractures in boys with Duchenne muscular dystrophy. Clin Pediatr (Phila) 2003;42:353-6.

[18] Ahmed SF, Horrocks IA, Patterson T, et al. Bone mineral assessment by dual energy X-ray absorptiometry in children with inflammatory bowel disease: evaluation by age or bone area. J Pediatr Gastroenterol Nutr 2004;38:276-80.

[19] Cole TJ, Freeman JV, Preece MA. British 1990 growth reference centiles for weight, height, body mass index and head circumference fitted by maximum penalized likelihood. Stat Med 1998;17:407-29.

[20] Freeman JV, Cole TJ, Chinn S, Jones PR, White EM, Preece MA. Cross sectional stature and weight reference curves for the UK, 1990. Arch Dis Child 1995;73:17-24.

[21] Bishop N, Arundel P, Clark E, et al. Fracture prediction and the definition of osteoporosis in children and adolescents: the ISCD 2013 Pediatric Official Positions. J Clin Densitom 2014;17:275-80. 
[22] Cooper C, Dennison EM, Leufkens HG, Bishop N, van Staa TP. Epidemiology of childhood fractures in Britain: a study using the general practice research database. J Bone Miner Res 2004;19:1976-81.

[23] King WM, Ruttencutter R, Nagaraja HN, et al. Orthopedic outcomes of long-term daily corticosteroid treatment in Duchenne muscular dystrophy. Neurology 2007;68:1607-13. [24] Ma J, McMillan HJ, Karaguzel G, et al. The time to and determinants of first fractures in boys with Duchenne muscular dystrophy. Osteoporos Int 2017;28:597-608.

[25] Wong BL, Rybalsky I, Shellenbarger KC, et al. Long-Term Outcome of Interdisciplinary Management of Patients with Duchenne Muscular Dystrophy Receiving Daily Glucocorticoid Treatment. J Pediatr 2017;182:296-303 e291.

[26] Straathof CS, Overweg-Plandsoen WC, van den Burg GJ, van der Kooi AJ, Verschuuren JJ, de Groot IJ. Prednisone 10 days on/10 days off in patients with Duchenne muscular dystrophy. J Neurol 2009;256:768-73.

[27] Singh A, Schaeffer EK, Reilly CW. Vertebral Fractures in Duchenne Muscular Dystrophy Patients Managed With Deflazacort. J Pediatr Orthop 2016.

[28] Halton J, Gaboury I, Grant R, et al. Advanced vertebral fracture among newly diagnosed children with acute lymphoblastic leukemia: results of the Canadian SteroidAssociated Osteoporosis in the Pediatric Population (STOPP) research program. J Bone Miner Res 2009;24:1326-34.

[29] Rodd C, Lang B, Ramsay T, et al. Incident vertebral fractures among children with rheumatic disorders 12 months after glucocorticoid initiation: a national observational study. Arthritis Care Res (Hoboken) 2012;64:122-31.

[30] Cummings EA, Ma J, Fernandez CV, et al. Incident Vertebral Fractures in Children With Leukemia During the Four Years Following Diagnosis. J Clin Endocrinol Metab 2015;100:3408-17.

[31] Ward LM, Konji VN, Ma J. The management of osteoporosis in children. Osteoporos Int 2016;27:2147-79. 
[32] Alos N, Grant RM, Ramsay T, et al. High incidence of vertebral fractures in children with acute lymphoblastic leukemia 12 months after the initiation of therapy. $\mathrm{J}$ Clin Oncol 2012;30:2760-7.

[33] Dal Osto LC, Konji VN, Halton J, et al. The Spectrum of Recovery From FractureInduced Vertebral Deformity in Pediatric Leukemia. Pediatr Blood Cancer 2016;63:1107-10.

[34] Lentle B, Ma J, Jaremko JL, et al. The Radiology of Vertebral Fractures in Childhood Osteoporosis Related to Glucocorticoid Administration. J Clin Densitom 2016;19:81-8.

[35] Wood CL, Straub V, Guglieri M, Bushby K, Cheetham T. Short stature and pubertal delay in Duchenne muscular dystrophy. Arch Dis Child 2016;101:101-6.

[36] Zacharin M. Assessing the skeleton in children and adolescents with disabilities: avoiding pitfalls, maximising outcomes. A guide for the general paediatrician. J Paediatr Child Health 2009;45:326-31.

[37] Schoenau E, Neu CM, Mokov E, Wassmer G, Manz F. Influence of puberty on muscle area and cortical bone area of the forearm in boys and girls. J Clin Endocrinol Metab 2000;85:1095-8.

[38] Neu CM, Rauch F, Rittweger J, Manz F, Schoenau E. Influence of puberty on muscle development at the forearm. Am J Physiol Endocrinol Metab 2002;283:E103-7.

[39] Wood CL, Cheetham TD, Guglieri M, et al. Testosterone Treatment of Pubertal Delay in Duchenne Muscular Dystrophy. Neuropediatrics 2015;46:371-6.

[40] Koeks Z, Bladen CL, Salgado D et al. Outcomes in Duchenne Muscular Dystrophy: A Study of 5345 Patients from the TREAT-NMD DMD Global Database. J Neuromuscul Dis 2017;4:293-306.

[41] Goto M, Komaki H, Takeshita E et al. Long-term outcomes of steroid therapy for Duchenne muscular dystrophy in Japan. Brain Dev 2016;38:785-91.

[42] Angelini C, Pegoraro E, Turella E, Intino MT, Pini A, Costa C. Deflazacort in Duchenne dystrophy: study of long-term effect. Muscle Nerve 1994;17:386-91.

[43] Pradhan S, Ghosh D, Srivastava NK, et al. Prednisolone in Duchenne muscular dystrophy with imminent loss of ambulation. J Neurol 2006;253:1309-16. 
[44] Birnkrant DJ, Bushby K, Bann CM, Alman BA, Apkon SD, Blackwell A, et al. Diagnosis and management of Duchenne muscular dystrophy, part 2: respiratory, cardiac, bone health, and orthopaedic management. Lancet Neurol. 2018;17:347-61.

\section{Legend to figures}

Figure 1: $\quad$ Anatomical location of non-VFs in boys with DMD.

Of the 91 boys, 37 developed non-VF (including 1 boy with non-VF and VF).

The 37 boys sustained a total of 43 non-VFs.

[VF: vertebral fracture; DMD: Duchenne muscular dystrophy].

Figure 2: $\quad$ Probability of fracture in boys with DMD against age and duration of GC exposure

Horizontal dotted line refers to $50 \%$ probability of fracture (Fig a, and b).

Vertical continuous line refers to mean age of loss of ambulation of boys with DMD in our cohort (Fig a). Vertical dotted lines refers to \pm 1 standard deviation from the mean of age of loss of ambulation (Fig a).

[DMD: Duchenne muscular dystrophy; VF: vertebral fracture; GC:

glucocorticoid]

(a) Probability of first symptomatic fracture in DMD over time (against age) using Kaplan-Meier analysis

The probability of developing first symptomatic fracture (symptomatic VF and non-VF) was $50 \%$ by 12.8 years of age. (Censored cases are shown as the crosses on Kaplan-Meier graph). Cases with previous GC treatment were also included.

(b) Probability of first symptomatic fracture in DMD in relation to duration of GC exposure using Kaplan-Meier analysis

The probability of developing first symptomatic fracture (symptomatic VF and non-VF) was $50 \%$ after 6.5 years of GC exposure. (Censored cases 
are shown as the crosses on Kaplan-Meier graph). Cases with previous GC treatment were also included.

\begin{tabular}{|c|c|c|}
\hline & n (\%) & $\begin{array}{c}\text { Median }\left(25^{\text {th }}, 75^{\text {th }}\right. \\
\text { centile })\end{array}$ \\
\hline Age (years) & $91 / 91(100 \%)$ & $11.0(7.8,15.0)$ \\
\hline Height SDS & $76 / 91(84 \%)$ & $-1.4(-2.7,-0.8)$ \\
\hline BMI SDS & $76 / 91(84 \%)$ & $, 2,2)$ \\
\hline Non-ambulant cohort & $46 / 91(51 \%)$ & \\
\hline Age at loss of ambulation (years) & $46 / 46(100 \%)$ & $.8,11.7)$ \\
\hline Length of non-ambulation state (years) & 40 & $2.9(1.5,6.0)$ \\
\hline Current GC treatment & & \\
\hline Previous GC treatment & & \\
\hline GC naïve & $0 \%)$ & \\
\hline Age at start of GC (years) & $\%$ & $5.5(4.4,6.6)$ \\
\hline Duration of GC therapy (years) & $82 / 82(100 \%)$ & $5.2(2.4,8.0)$ \\
\hline $\begin{array}{c}\text { Hydrocortisone equivalent dose }\left(\mathrm{mg} / \mathrm{m}^{2} / \mathrm{da}\right. \\
\text {-Daily deflazacort } \\
\text {-Daily prednisolone } \\
\text {-Pulsed prednisolone } \\
\text {-Pulsed deflazacort } \\
\text {-Unknown GC regimen (Clinical Trial) }\end{array}$ & $\begin{array}{c}23 / 59(40 \%) \\
16 / 59(27 \%) \\
13 / 59(22 \%) \\
1 / 59(2 \%) \\
6 / 59(10 \%)\end{array}$ & $\begin{array}{c}94.0(45,138) \\
69.5(64.8,75.8) \\
31.0(13.5,37.0) \\
66.0\end{array}$ \\
\hline
\end{tabular}

Table 1: Clinical characteristics of boys with DMD in Scotland at last clinic visit SDS: standard deviation score; BMI: body mass index; GC: glucocorticoid; mg: milligram; $\mathrm{m}^{2}$ : meter square; DMD: Duchenne muscular dystrophy 
Number

of boys

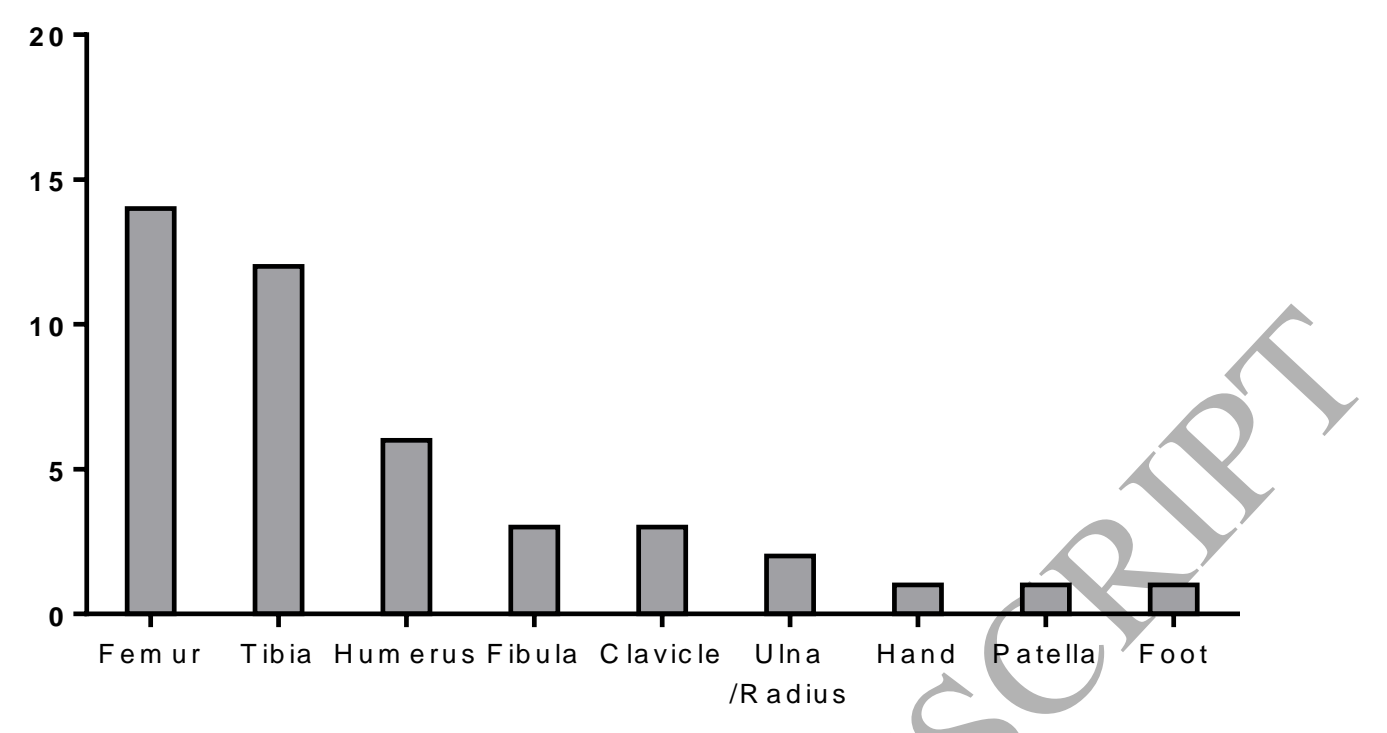

Figure 1 


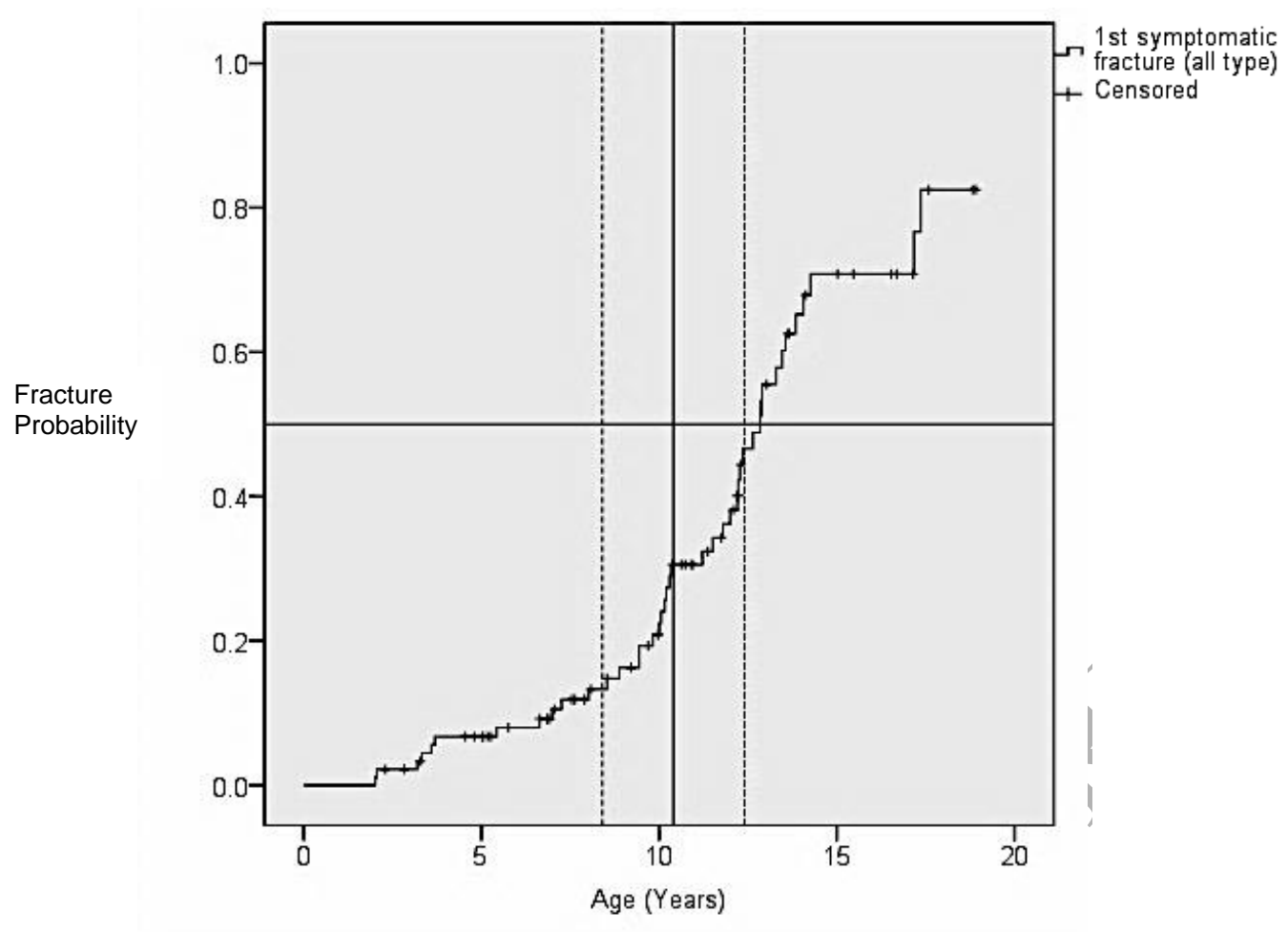

Figure 2(a)

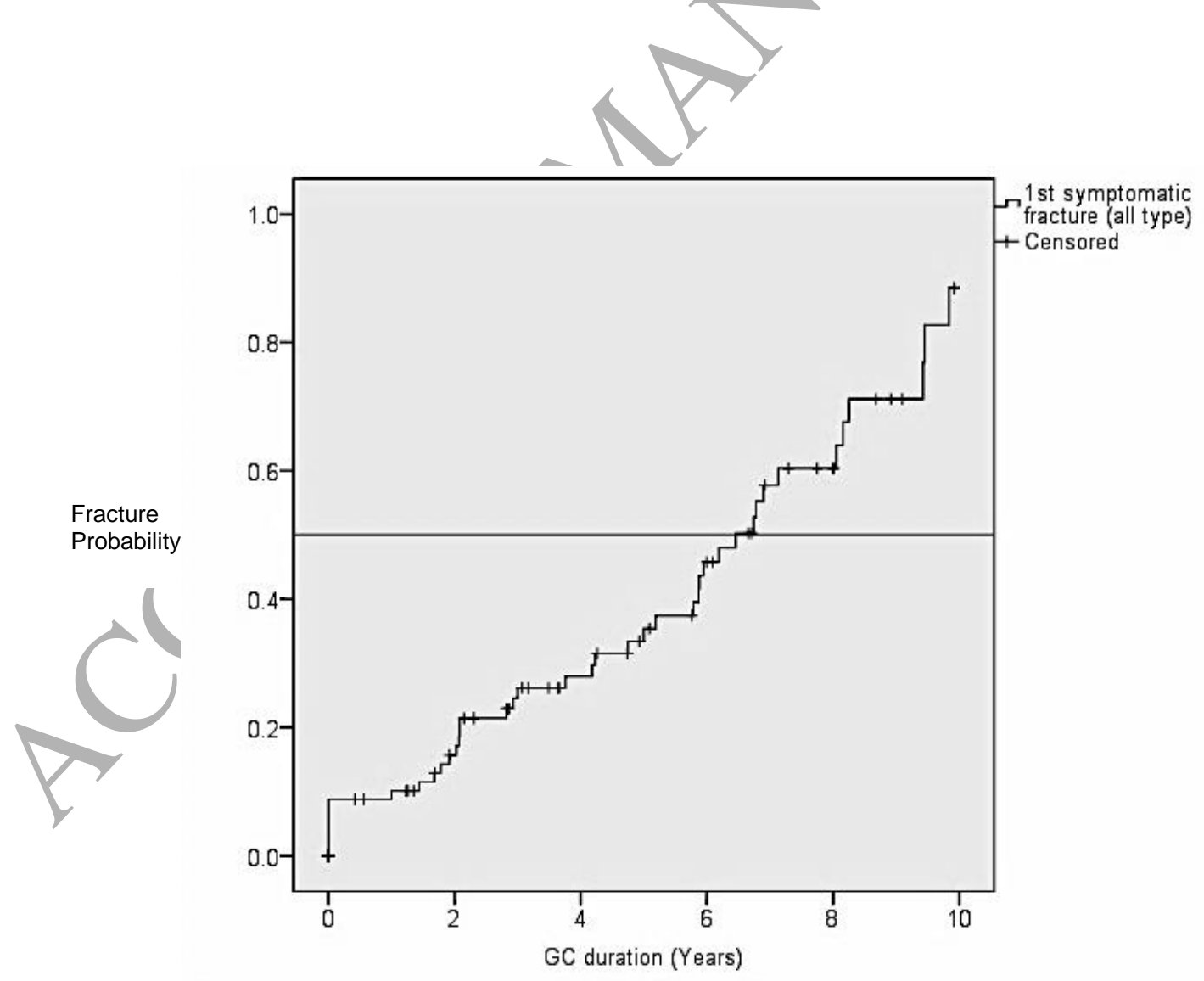

Figure 2(b) 